УДК 81'42

ББК 81.18

DOI: https://doi.org/10.17308/lic.2021.1/3233

\title{
ФУНКЦИИ ТЕРМИНОВ ЦВЕТООБОЗНАЧЕНИЯ В ХУДОЖЕСТВЕННОМ ТЕКСТЕ
}

\author{
Я. Е. Матросова \\ Московский государственный лингвистический университет
}

\section{FUNCTIONS OF COLOR TERMS IN LITERARY TEXT}

\author{
Ya. E. Matrosova \\ Moscow State Linguistic University
}

\begin{abstract}
Аннотация: в статье рассматривается вопрос о функционировании терминов изветообозачнения в тексте. Обосновывается необходимость выработки новой классификации функций терминов цветообозначения, ориентированной на анализ текстов оригиналов и их переводов. Выделяются номинативная, символическая и образно-структурная функции. Номинативная подразделяется на собственно-номинативную, уточняюще-номинативную и художественно-номинативную. Суть этой функции состоит в номинации цвета, при этом особенность уточняюще-номинативного подтипа заключается в том, что она используется для семантической дифференцииции названий сходных оттенков, тогда как в художественно-номинативном подтипе в условиях синонимии цветообозначений предпочтение отдается менее узуальным ввиду их большего стилистического потенциала. В рамках символической функиии рассматриваются различные типы символов: архетипический (наиболее универсальный, но в то же время и наиболее размытый, в основном связан с эмоциональной сферой), культурный (связан с отсылкой к конкретнылм объектам или явлениям культуры) и авторский (связь между термином иветообозначения и нецветовым значением задается непосредственно в тексте и не существует за его пределами). Как и символическая функиия, образно-структурная способствует созданию двуплановости текста, но при этом термины ивета в ней не имеют самостоятельных дополнительных значений, хотя участвуют в механизме формирования целостного текста, в том числе встраиваясь в другие подсистемы. В рамках даже одного иветового термина функиии могут сосуществовать и дополнять друг друга. Парадигматически нейтральный термин цвета, попадая в текст, может приобретать синтагматическую маркированность и повылать свой стилистический динамический ранг.
\end{abstract}

Ключевые слова: иветообозначения, маркированность, динамические ранги, художественный текст, динамическое восприятие.

\begin{abstract}
It testifies elaboration of a noval classification of color terms tailored to analysis of source texts and their translations. The classification comprises a nominative, a symbolic, and an imagery structural functions. The nominative function has three types which are as follows: basic, specifying, and evocative ones. The only thing this function does is nominating a color. At the same time, the spesifying type also allows to highlight the semantic difference between color names of two similar hues, while the evocative one is used when a color term is chosen for its expressive features comparing to a synonomic but more commonly used term. Three types of symbols are named within the symbolic function: an archetypical (the most common but also the least specific in meaning), a cultural (relating to something created by mankind), and a local one (existing in a particular text). As well as the symbolic function, the imagery structural function takes part in forming a complex two-dimention structure of the text, though these color terms do not have extra meanings. Several functions may symbiose within one color term. When in text, even a stylistically neutral color term are able to gain a syntagmatic markedness and increase its stylistic dynamic rank.
\end{abstract}

Key words: color terms, markedness, dynamic rank, literary text, dynamic perception.

(C) Матросова Я. Е., 2021

Контент доступен под лицензией Creative Commons Attribution 4.0 License.

The content is available under Creative Commons Attribution 4.0 License. 


\section{Введение}

Изучение функций терминов цветообозначения (ТЦО) представляет не только теоретический, но и практический интерес, поскольку определение функции ТЦО в художественном тексте является одним из важных факторов предпереводческого анализа, на основе которого выстраивается стратегия перевода. Таким образом, переводчику желательно иметь для работы некую систему функций, на которую он мог бы опираться.

Функции ТЦО уже не раз становились объектом внимания лингвистов: различные системы предлагали такие исследователи, как Т. И. Вендина [1], В. И. Макеенко [2], В. Г. Кульпина [3; 4] и Е. А. Горн [5]. Каждая из этих систем функций обладает своими достоинствами, однако ни одна в полной мере не подходит для поставленной нами задачи.

Например, классификации Т. И. Вендиной и В. Г. Кульпиной ориентированы на описание функций ТЦО в языке, но неприменимы для текстов. В. И. Макеенко выделяет в качестве самостоятельной функции только номинативную, не называя других, хотя и косвенно описывает их. Особенно примечательна классификация Е. А. Горн, поскольку функции в ней отражают систему типов выдвижения: сцепление, конвергенция, сильная позиция и обманутое ожидание. Однако, на наш взгляд, этот подход не совсем удачен, поскольку сильная позиция все же не может считаться функцией ТЦО, а построение обманутого ожидания на основе ТЦО если и встречается в литературе, то крайне редко.

Система функций ТЦО, пригодная для практической работы переводчика, на наш взгляд, должна отвечать нескольким критериям:

1) описывать функции ТЦО в тексте, а не языке в целом;

2) быть последовательной, т. е. в одной системе функции не должны выделяться на основе различных принципов;

3) быть универсальной, т. е. такой, которая могла бы классифицировать любой случай употребления ТЦО в тексте;

4) быть относительно компактной, чтобы не усложнять ее применение на практике.

Поскольку классификации функций всех перечисленных выше авторов не отвечают хотя бы одному из названных критериев, нам представляется целесообразным предложить собственную классификацию.

На основе опыта предшественников и собственных наблюдений мы выделяем три основные функции: номинативную, символическую и образно-структурную. Номинативная функция при этом разделяется на три подвида: собственно-номинативный, уточняюще-номинативный и художественно-номина- тивный. Символическая функция, в отличие от номинативной, не требует подобного разделения, но и нельзя не отметить, что за ТЦО может скрываться символизм разного рода: архетипический, культурный и авторский.

\section{Номинативная функция}

В целом номинативную функцию можно считать базовой и самой простой: ТЦО в этом случае непосредственно указывают на цвет объекта (синие штоpbl, зеленое платье и т. д.) и не играют никакой роли в смыслоформировании текста. В то же время и у этой простой функции есть три разновидности.

Собственно-номинативый подтип характерен прежде всего для базовых (в терминологии Берлина и Кея [6]) ТЦО. ТЦО этого подтипа лишь называют цвет того или иного объекта, не подразумевая никаких дополнительных смыслов и не внося двуплановости.

He wore blue (1) linen shorts that buttoned to his shirt, his hair was snow white (2) and stuck to his head like duckfluff; he was a year my senior but I towered over him. (To Kill a Mockingbird, Harper Lee)

Пример (1) хорошо это иллюстрирует: цвет одежды героя неважен для дальнейшего повествования, он вполне мог бы быть и любым другим.

В примере (2) ТЦО тоже выполняет номинативную функцию, но в этом случае его следует отнести ко второй ее разновидности: уточняюще-номинативному подтипу. Его особенность состоит в том, что цвет не просто называется, а уточняется его оттенок. В приведенном примере уточнение snow white показывает, что волосы мальчика были не просто светлыми, а «совсем былыми» (пер. Н. Галь). То есть автор стремится не просто назвать цвет, а детализировать оттенок. Н. Б. Бахилина приводит в качестве примера красный цвет: «Поскольку и в качестве цветообозначения слово красный весьма объемно (от светло-красного, розового до вишневого, бордо, терракотового и пр.), оно не очень выразительно, и художники слова, особенно поэты, охотнее употребляют слова, обозначающие более точные (и более экспрессивные) оттенки красного - алый, багровый, багряный и пр.» [7, c. 173]. Очевидно, что денотаты терракотовый и бордо частично отличаются друг от друга, хотя оба цвета можно в целом считать «красными».

Следует подчеркнуть, что данную цитату мы приводим не только, чтобы раскрыть причины использования слов, выражающих оттенки, но и указать на отказ авторов от использования именно базовых ТЦО. Фактически же Н. Б. Бахилина приводит две возможные причины обращения к гипонимическим ТЦО, и с уточняюще-номинативным подтипом номинативной функции связана точность. 
Само разнообразие цветообозначений как лексической группы в языке объясняется в том числе (но не только) желанием носителей точнее вербализовать тот или иной цвет, указать на его физические характеристики, т. е. тон, светлоту и насыщенность, а не ограничиваться лишь основными ТЦО.

В случае употребления ТЦО в художественно-номинативном подтипе номинативной функции, на первый взгляд, происходит то же самое: для номинации цвета используются сложные (the color of chopped liver) либо простые конкретизирующие [8] (uафpaновый) ТЦО. Однако здесь на передний план выходит цель не конкретизировать оттенок, а внести большую степень выразительности. Из приведенной выше цитаты Н. Б. Бахилиной видно, что лексемы, выражающие оттенки - не просто более точные, но и более экспрессивные. Цель их использования в художественно-номинативном подтипе функции состоит не в точном указании на цвет, не в его дифференциации относительно других оттенков или фокального цвета [9] / лучшего образца цвета [10], а в отказе от наиболее узуальных (и следовательно, более стертых) обозначений цвета в пользу более выразительных. Другими словами, художественно-номинативный подтип отличается от уточняюще-номинативного тем, что в первом случае использованное менее узуальное ТЦО синонимично какому-либо более узуальному и употребляется с целью лексически разнообразить текст, а во втором - ТЦО, выражающее оттенок, денотативно противопоставляется базовому (либо другим оттеночным).

On her neck, peeking from beneath the thrashing scarf, was a freshly healed scratch the color of raspberry jam. (West of Sunset, S. O'Nan)

Приведенный пример показывает, что ТЦО the color of raspberry jam здесь могло бы быть заменено более употребительным red или хотя бы raspberry red. Однако автор делает выбор в пользу окказионального варианта, что представляется совершенно естественным, особенно в контексте художественной литературы.

\section{Символическая функция}

Почти всегда среди функций ТЦО лингвистами выделяется и символическая. О ней писали, например, Т. И. Вендина [1] и В. И. Макеенко [2]. Суть символической функции состоит в том, что в определенном контексте у ТЦО появляется дополнительное значение: цветонаименование начинает не только называть цвет объекта, но и отсылать к другому объекту или понятию, описываемому в тексте или находящемуся за его пределами.

Отметим, что подобная связь может быть выражена как эксплицитно, когда связь между ТЦО и скрытым за ним символом непосредственно описы- вается в тексте, так и имплицитно, когда интерпретатор осознает ее сразу либо постепенно по мере прочтения, т. е. в динамическом восприятии текста. Скорость декодирования скрытого значения, в свою очередь, во многом зависит от типа символа, подразумеваемого под ТЦО. Представляется оптимальным выделить три типа цветового символизма: архетипический, культурный и авторский.

Под архетипическим символизмом мы понимаем здесь наиболее общие и размытые, но универсальные ассоциативные связи, присущие тому или иному ТЦО. Например, для носителей и английского, и русского языков с черным цветом (и темными оттенками) ассоциируются несчастье, траур, опасность и т. д. В художественной литературе именно темные тона используются чаще всего для описаний, связанных со смертью или страхом, отсюда возникает, например, и литературный архетип «черного человека» [11]. Светлые тона, напротив, связаны с радостью, счастьем, спокойствием.

Некоторые предположения можно строить и о других ТЦО: зеленом, как связанном с природой и молодостью, красном как символе крови и опасности и т. д. На этом этапе неизбежно возникает кажущаяся привлекательной идея создания некоего словаря цветов и их «символических значений». Конечно, составить списки ассоциаций можно для любого ТЦО, но подобные ассоциативные ряды по определению будут довольно обширны и разнородны, и словарем их назвать нельзя. Это подтверждает и практика. Попытки выявления нецветовых значений у ТЦО предпринимали многие исследователи: Е. В. Воевода [12], Н. С. Братчикова [13], Е. А. Власова [14] и др. Однако полученные ими результаты анализа даже базовых ТЦО крайне противоречивы, причем как в рамках одного исследования, так и при их сравнении. Так, по результатам, полученным Е. А. Власовой, английское white означает и страх, и радость, по данным Е. В. Воеводы, русское синий - и огонь, и воду. У Е. В. Воеводы голубой подразумевает радость, тогда как у Н. С. Братчиковой - равнодушие, безразличие. Сравнение выявляет и некоторые другие недостатки, но сама по себе невоспроизводимость результатов не дает возможности относиться к ним как к научно достоверным.

Для большинства ТЦО выявление символических значений не только невозможно, но и непрактично - при всем множестве ассоциаций, которые могут назвать при опросе носители, в каждом конкретном случае актуализируется только определенное значение, которое зависит от самого произведения.

Во многом набор значений в ассоциативном ряду обусловлен культурным символизмом. Под ним мы понимаем связь, которая также объединяет ТЦО с неким затекстовым понятием, но уже не таким раз- 
мытым, как в случае архетипического символизма. Разумеется, сами по себе цвета не могут иметь нецветовых значений, и архетипический символизм тоже обусловлен культурным контекстом (как известно, в некоторых культурах как раз бельй является знаком траура, а черныци - радости). Разница, на наш взгляд, заключается в том, что архетипические символы связаны с психологическими понятиями, тогда как культурные - с деятельностью человека, они более конкретны и материальны.

В качестве примера можно привести исторический роман Сьюзан Хиггенботам The Queen of Last Hopes, посвященный Маргарите Анжуйской. Поскольку события романа разворачиваются в период Войны Алой и Белой розы, ТЦО white и red (в том числе и там, где речь не идет о розах-символах) соответствуют противоборствующим партиям Йорков и Ланкастеров соответственно. Автору нет необходимости пояснять это, и выявить связь интерпретатору позволяет не текст, а собственные фоновые знания, поскольку Война роз - реальный исторический период. Таким образом, связь между ТЦО и стоящим за ним символом известна читателю еще до знакомства с произведением и не зависит от него.

Там же, где символическая связь существует только в рамках текста, можно говорить об авторском символизме. Связь между ТЦО и подразумеваемым под ним значением задается самим автором, а не существует в сознании интерпретатора изначально, она носит частный характер.

Так, например, в романе Ф. С. Фицджеральда «Великий Гэтсби» главный герой каждый вечер смотрит на зеленый огонек на противоположном берегу залива, отождествляя этот зеленый свет с надеждами и мечтами о счастье с возлюбленной. Эта связь существует и имеет смысл только в контексте романа. Хотя символ сравнительно легко интерпретируется читателем, сам автор достаточно явно поясняет его в конце произведения:

Gatsby believed in the green light, the orgastic future that year by year recedes before us. (The Great Gatsby, F. S. Fitzgerald)

Наконец, третья выделяемая нами функция - образно-структурная. Ее суть заключается в том, что ТЦО встраивается в образно-ассоциативную структуру произведения, участвуя в смыслоформировании целостного текста как самостоятельно, так и в составе других семантических цепочек.

\section{Образно-структурная функция}

В отличие от символической функции, образно-структурная не подразумевает наличие у отдельных ТЦО каких-либо дополнительных смыслов, сами по себе они ничего не значат, но могут, как пишет И. В. Макеенко, «выполнять ряд стилистических задач, связанных с организацией всего текста или отдельных его частей» [2, с. 105] и «включаться в структуру всего художественного произведения» [Там же, с. 106].

Одним из показательных примеров может служить рассказ Дж. Д. Сэлинджера «И эти губы, и глаза зеленые». Уже в самом начале произведения, в сильной позиции, упоминается, что глаза героини необычного насыщенно-синего оттенка.

The girl heard him as if from a distance, and turned her face toward him, one eye-on the side of the lightclosed tight, her open eye very, however disingenuously, large, and so blue as to appear almost violet. (Pretty Lips and Green my Eyes, J. D. Salinger)

Примечательно, что имена персонажей - Ли, Джоанна, Артур - читатель узнает из телефонного разговора, тогда как автор ни разу не упоминает ни одного имени. Ли и Джоанна упоминаются в тексте лишь по отдельным чертам внешности (о внешности Артура читателю не сообщается ничего, так как тот остается только голосом в телефонной трубке). Автор называет Ли не иначе как the grayhaired man, а единственное описание Джоанны - синие глаза, о чем на протяжении короткого рассказа говорится четыре раза. Регулярность повтора в небольшом тексте неизбежно обращает на себя внимание.

Тем более парадоксальным, на первый взгляд, кажется вынесенная в заглавие строка из стихотворения, которое Артур когда-то посвятил будущей жене: pretty mouth and green my eyes. Герой знает, что у его жены не зеленые глаза, но пишет о них именно так. Однако из телефонного разговора столь явно подчеркнутое противоречие ТЦО green и blue становится понятно: Артур рассказывает другу, что они с женой друг другу совершенно не подходят, хотя еще перед свадьбой предчувствовал, что брак удачным не будет ("I ignored 'em. I ignored all my goddam flashes.”) Возможно, как раз в пору влюбленности он создал себе образ, который отличался от настоящей Джоанны, и это несоответствие находило отражение даже во внешности. Отметим, что ТЦО в образно-структурной функции необязательно должен быть одним и тем же - один и тот же цвет может выражаться по-разному. В рассмотренном примере глаза Джоанны описываются как blue, violet и даже sea shells.

Таким образом, ТЦО в данной функции играют весьма важную роль в смыслоформировании рассказа. Им самим по себе не соответствуют никакие конкретные нецветовые значения, как в случае символической функции, но их роль, очевидно, не сводится и к простой номинации цвета. Благодаря таким типам выдвижения, как сцепление и сильная позиция, они встраиваются в контекст и помогают декодировать авторский замысел. 
Понятие выдвижения получило широкое распространение в отечественной лингвистике благодаря И. В. Арнольд [15]. По сложившейся традиции, к основным типам выдвижения относят сцепление, конвергенцию, сильную позицию и обманутое ожидание, что подталкивает исследователей рассматривать примеры выдвижения в статическом аспекте. Наряду с этим в современной лингвистике получают развитие идеи динамического выдвижения.

Для пояснения этой идеи необходимо сказать о двух параметрах, без которых невозможен анализ ТЦО в тексте, а именно о стилистической маркированности и динамических рангах.

\section{Стилистическая маркированность и динамические ранги}

Понятие маркированности обычно рассматривают как некое парадигматическое свойство, т. е. исходно присущее единице языка. Однако, как показывает В. Л. Наер, маркированность может быть и синтагматической, т. е. приобретаемой в тексте [16]. В сущности, из пяти выделенных им типов маркированности одна является парадигматической (которую он также называет имманентной), а четыре - синтагматическими.

Следовательно, ТЦО тоже может быть присуща как парадигматическая, так и синтагматическая маркированность. Парадигматическая в некоторых случаях фиксируется в словарях, хотя не каждый редкий, заимствованный или поэтичный ТЦО получает соответствующую помету. Особенность синтагматической маркированности состоит в том, что в определенном контексте ее может получать и совершенно нейтральный ТЦО, а имманентная маркированность может усиливаться.
Это подводит нас к понятию стилистических динамических рангов, предложенному Д. В. Псурцевым в рамках лингвостилистического подхода к проблеме смыслоформирования художественного текста [17]. В соответствии с этой концепцией динамический ранг может быть нулевым, младшим, старшим или высшим старшим. Нулевой ранг подразумевает, что элементы «нейтральны относительно своего первичного синтагматического контекста», младший «задается прагматикой непосредственного контекста», элементы старшего ранга входят в «выдвигающуюся структуру образно-ассоциативных компонентов текста, которая актуализируется надлинейно благодаря ассоциативно-повторным механизмам» $[18$, с. 120]. При этом старшие ранги становятся высшими, если они значимы для смыслоформирования целостного текста и имеют «статус высшей стилистической релевантности» [18, с. 121]. Поэтому вне зависимости от наличия исходной маркированности, рассматривая ТЦО в тексте, обратить внимание следует на синтагматическую маркированность.

То есть для оценки роли ТЦО в тексте необходимо определить, маркирован ли он, является ли маркированность исходной (т. е. номенклатурной, языковой, парадигматической) или приобретенной (т. е. синтагматической, текстовой) и какой динамический ранг получает ТЦО при динамическом восприятия текста. Сопоставляя параметры маркированности и динамических рангов, можно выявить некоторые закономерности, что можно представить в виде следующей схемы (рисунок).

В тех случаях, когда парадигматически нейтральные ТЦО сохраняют нейтральность в синтагматике, т. е. имеют в тексте нулевой ранг, речь идет о соб-

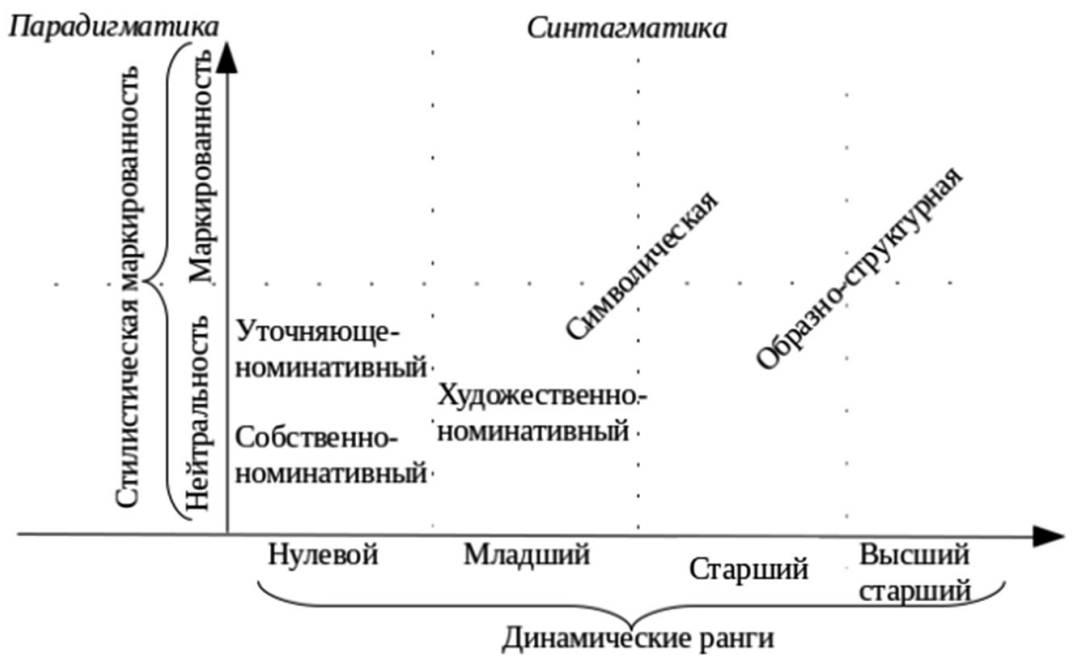

Рисунок. Соотношение стилистической маркированности и динамических рангов у различных функций ТЦО 
ственно-номинативной или уточняюще-номинативном подвиде номинативной функции.

Художественно-номинативный подвид характеризуется исходной маркированностью, но сама по себе номинативная функция подразумевает, что роль ТЦО в тексте невелика, поэтому для этого подвида характерен младший ранг.

Вне зависимости от наличия номенклатурной маркированности ТЦО в символической функции могут иметь в тексте младший ранг, но могут и получать старший, если образуют семантические цепочки.

Если ТЦО в образно-структурной функции образуют самостоятельные цепочки либо входят в состав других, стилистически значимых, они приобретают старший ранг. Если же в результате цепочки участвуют в итоговой конструкции надлинейного выдвижения, ранг таких ТЦО можно назвать высшим старшим.

Хотя в предложенной нами системе выделяется три самостоятельные функции, на практике тот или иной ТЦО может выполнять не одну, а две и даже три функции одновременно. При том что символическая или образно-структурная функции могут быть ведущими, номинативная присутствует в ТЦО всегда как основная или вспомогательная. Это объясняется тем, что и в тех случаях, когда ТЦО является элементом создания двуплановости/многоплановости, он все равно указывает на цвет, и если подтекстное значение читателем может быть не распознано, прямое цветовое значение будет понято в любом случае.

\section{Заключение}

Итак, термины цветообозначения наряду с другими стилистически значимыми элементами могут играть самостоятельную или вспомогательную роль в создании многоплановости текста и его целостном смыслоформировании. Для анализа роли ТЦО в тексте мы предлагаем опираться в том числе на следующую систему функций: номинативная (с собственно-номинативным, уточняюще-номинативным и художественно-номинативным подвидами), символическая (символ при этом может быть архетипическим, культурным и авторским) и образно-структурная. Важным параметром анализа ТЦО является его стилистическая маркированность, однако, поскольку речь идет о функционировании ТЦО в тексте, необходимо обращать внимание не только на парадигматическую, но и синтаксическую маркированность и, соответственно, наличие у ТЦО того или иного динамического ранга.

\section{ЛИТЕРАТУРА}

1. Вендина Т. И. Цвет в этнокультурной системе русского, старославянского и древнерусского языков // Славянский альманах. М. : Индрик, 1999. URL: https:// cyberleninka.ru/article/n/tsvet-v-etnokulturnoy-sistemerusskogo-staroslavyanskogo-i-drevnerusskogo-yazykov

2. Макеенко В. И. Семантика цвета в разноструктурных языках : универсальное и национальное : дис. ... канд. филол. наук. Саратов, 1999. 258 с.

3. Кульпина В. Г. Лингвистика цвета : термины цвета в польском и русском языках. М. : Московский лицей, 2001. 470 c.

4. Кульпина В. Г. Программа спецкурса «Актуальные проблемы лингвистики цвета как научного направления сопоставительного языкознания» // Вестник МГУ. Cep. 19. Лингвистика и межкультурная коммуникация. 2008. № 2. URL: https://cyberleninka.ru/article/n/programma-spetskursa-aktualnye-problemy-lingvistiki-tsveta-kak-nauchnogo-napravleniya-sopostavitelnogo-yazykoznaniya

5. Горн E. А. Цветообозначения в художественном тексте на английском и русском языках в сопоставительно-переводческом аспекте : на материале современной английской литературы : дис. ... канд. филол. наук. М., 2014. 210 c.

6. Berlin B., Kay P. Basic Color Terms, Their Universality and Evolution. Los Angeles : Center for the Study of Language and Inf., 1969. 210 p.

7. Бахилина Н. Б. История цветообозначений в русском языке. М. : Наука, 1975. 288 с.

8. Матросова Я. Е. Морфологические классификации русских цветообозначений, представленных в языке художественной литературы // Вестник Нижегор. гос. лингв. ун-та им. Н. А. Добролюбова. 2016. № 36. C. $61-74$.

9. Heider E. R. Probabilities, Sampling, and Ethnographic Method : The Case of Dani Color Names // Man, New Series. 1972. Vol. 7, № 3. Pp. 448-466.

10. Harkness $S$. Universal aspects of learning colour codes : a study in two cultures // Ethos. 1973. Vol. 1, № 3. Pp. 175-200.

11. Большакова А. Ю. Литературный архетип // Литературная учеба. 2001. № 6. С. 169-173.

12. Воевода E. В. Цветовосприятие и ассоциативные поля в русском и английском языках // Научный вестник Воронеж. гос. архит.-строит. ун-та. 2012. № 2. URL: https://mgimo.ru/upload/iblock/df6/df66b41e6f203f67692 e719e14f8239e.pdf

13. Братчикова Н. С. Цветовая картина мира в русском и финском языковом сознании // Вестник Моск. гос. лингв. ун-та. 2006. № 529. С. 186.

14. Власова E. A. Символика цветообозначений в британском и американском вариантах английского языка : автореф. дис. ... канд. филол. наук. Оренбург, 2008. 24 c.

15. Арнольд И. В. Стилистика. Современный английский язык. 10-е изд. М. : Флинта : Наука, 2010. 384 с.

16. Наер В. Л. Прагматическая сущность стилистической маркированности // Проблемы стилистической маркированности. 1990. № 356. С. 4-9.

17. Псуриев Д. В. Смыслоформирование художественного текста : теоретические основания лингвости- 
листического подхода : дис. ... д-ра филол. наук. М., 2009. 498 c.

18. Псуриеев Д. В. Стилистическая маркированность : виды или динамические ранги? // Вестник Моск. гос. лингв. ун-та. 2009. Вып. 573. С. 118-128.

\section{REFERENCES}

1. Vendina T. I. TSvet v ehtnokul'turnoj sisteme russkogo, staroslavyanskogo i drevnerusskogo yazykov [Color in ethnic and cultural system of Russian, Old Slavic, and Old East Slavic]. Slavyanskii al'manakh (Slavic Anthology). Moscow: Indrik, 1999. Available at: https://cyberleninka. ru/article/n/tsvet-v-etnokulturnoy-sisteme-russkogo-staroslavyanskogo-i-drevnerusskogo-yazykov

2. Makeenko V. I. Semantika tsveta v raznostrukturnykh yazykakh: universal'noe i natsional'noe [Semantics of Color in Languages of Different Structure: Common and Specific]. PhD Dissertation. Saratov, 1999. 258 p.

3. Kul'pina V. G. Lingvistika tsveta: Terminy tsveta $v$ pol'skom i russkom yazykakh. [Color in Linguistics: Color Terms in Polish and Russian]. Moscow: Moskovskii litsei, 2001. 470 p.

4. Kul'pina V. G. Programma spetskursa "Aktual'nye problemy lingvistiki tsveta kak nauchnogo napravleniya sopostavitel'nogo yazykoznaniya" [Modern Problems of Color in Linguistics from Comparative Perspective: Special Course Outline]. Vestnik MGU. Lingvistika i mezhkul'turnaya kommunikatsiya (Bulletin of Moscow State University. Linguistics in International Communication). Series 19. 2008. No. 2. Available at: https://cyberleninka.ru/article/n/ programma-spetskursa-aktualnye-problemy-lingvistiki-tsveta-kak-nauchnogo-napravleniya-sopostavitelnogo-yazykoznaniya

5. Gorn E. A. TSvetooboznacheniya v khudozhestvennom tekste na anglijskom i russkom yazykakh v sopostavitel'no-perevodcheskom aspekte: na materiale sovremennoj anglijskoj literatury [Color Terms in English and Russian Literal Texts from Comparative Perspective (a Study of Modern Eglish Literature)]. PhD Dissertation. Moscow, 2014. 210 p.

6.. Berlin B., Kay P. Basic Color Terms, Their Universality and Evolution. Los Angeles: Center for the Study of Language and Inf., 1969. 210 p.

7. Bakhilina N. B. Istoriya tsvetooboznachenij v russkom yazyke [History of Color Terms in the Russian Language]. Moscow: Nauka, 1975. 288 p.

8. Matrosova Ya. E. Morfologicheskie klassifikatsii russkikh tsvetooboznachenij, predstavlennykh $\mathrm{v}$ yazyke khudozhestvennoj literatury [Morphological Classifications

Московский государственный лингвистический университет

Матросова Я. Е., преподаватель кафедры переводоведения и практики перевода английского языка

E-mail:ya.matrosova@linguanet.ru of Colour Terms in Russian Literature]. Nizhny Novgorod Linguistics University Bulletin (Vestnik Nizhegorodskogo gosudarstvennogo lingvisticheskogo universiteta im. N. A. Dobrolyubova). 2016. No. 36. Pp. 61-74.

9. Heider E. R. Probabilities, Sampling, and Ethnographic Method: The Case of Dani Color Names. Man, New Series. 1972. Vol. 7, No. 3. Pp. 448-466.

10. Harkness S. 1973. Universal aspects of learning colour codes: A study in two cultures. Ethos. 1973. Vol. 1, No. 3. Pp. 175-200.

11. Bol'shakova A. Yu. Literaturnyj arkhetip [Literal achetype]. Literaturnaya ucheba (Literature Training). 2001. No. 6. Pp. 169-173.

12. Voevoda E. V. TSvetovospriyatie i assotsiativnye polya $\mathrm{v}$ russkom i anglijskom yazykakh [Color Perception and Association Field in Russian and English] Nauchnyi vestnik Voronezhskogo gosudarstvennogo arkhitekturno-stroitel'nogo universiteta (Scientific Bulletin of Voronezh State Unicersity of Architecture and Civil Engineering). 2012. No. 2. Available at: https://mgimo.ru/upload/iblock/ df6/df66b41e6f203f67692e719e14f8239e.pdf

13. Bratchikova N. S. TSvetovaya kartina mira v russkom i finskom yazykovom soznanii [Color World View in Russian and Finnish Language Consciousness]. Vestnik Moskovskogo gosudarstvennogo lingvisticheskogo universiteta (Bulletin of Moscow State Linguistic University). 2006. No. 529. P. 186.

14. Vlasova E. A. Simvolika tsvetooboznachenij v britanskom i amerikanskom variantakh anglijskogo yazyka [Symbolism of Color Terms in British and American English]. PhD Dissertation Abstract. Orenburg, 2008. 24 p.

15. Arnol'd I. V. Stilistika. Sovremennyj anglijskij yazyk [Stylistics. Modern English language]. 10 ${ }^{\text {th }}$ ed. Moscow: Flinta: Nauka, 2010. 384 p.

16. Naer V. L. Pragmaticheskaya sushhnost' stilisticheskoj markirovannosti [Pragmatic Aspect of Stylistic Markedness]. Problemy stilisticheskoi markirovannosti (Problems of Stylistic Markedness). 1990. No. 356. Pp. 4-9.

17. Psurtsev D. V. Smysloformirovanie khudozhestvennogo teksta: teoreticheskie osnovaniya lingvostilisticheskogo podkhoda [Sense Forming of Fiction Text: Theoretical Basics of Linguistic and Stylistic Approach] Habilitation thesis. Moscow, 2009. 498 p.

18. Psurtsev D. V. Stilisticheskaya markirovannost': vidy ili dinamicheskie rangi? [Stylistic Markedness: Types or Dymamic Ranks?] Vestnik Moskovskogo gosudarstvennogo lingvisticheskogo universiteta (Bulletin of Moscow State Linguistic University). 2009. No. 573. Pp. 118-128.

Moscow State Linguistic University

Matrosova Ya. E., Lecturer of the Theory and Practice of the English Translation and Interpreting Department

E-mail:ya.matrosova@linguanet.ru 
Поступила в редакиию 25 июля 2020 г.

Принята к публикачии 29 декабря 2020 2.

\section{Для цитирования:}

Матросова Я. Е. Функции терминов цветообозначения в художественном тексте // Вестник Воронежского государственного университета. Серия: Лингвистика и межкультурная коммуникация. 2021. № 1. С. 14-21. DOI: https://doi.org/10.17308/lic.2021.1/3233
Received: 25 July 2020

Accepted: 29 December 2020

\section{For citation:}

Matrosova $Y$. E. Functions of color terms in literary text. Proceedings of Voronezh State University. Series: Linguistics and Intercultural Communication. 2021. No. 1. Pp. 14-21. DOI: https://doi.org/10.17308/lic.2021.1/3233 